\title{
Relationship between Attitude Towards Guidance and Counseling Programme and Adjustment of Re-admitted Teenage Mothers in Kenyan Secondary Schools
}

\section{Christine Mwajuma Opondo}

\author{
Department of Psychology, \\ Maseno University, Maseno \\ Dr. Peter J.O. Aloka \\ Department of Psychology \& Educational Foundations, \\ Jaramogi Oginga Odinga University of Science \& Technology

\begin{abstract}
Dr. Pamela A. Raburu
Department of Psychology \& Educational Foundations, Jaramogi Oginga Odinga University of Science \& Technology
\end{abstract}

Doi: 10.1515/ajis-2017-0018

\section{Abstract}

Teenage motherhood is a worldwide problem with 36.4 million girls giving birth before the age of 18 years in developing world. The present study investigated the relationship between attitude towards guidance and counseling programme and adjustment of re-admitted teenage mothers in selected Kenyan secondary schools. The study employed Ex-post facto Research Design. The target population of the study was 242 readmitted teenage mothers from selected schools in Ugenya Sub County. The sample size comprised 138 readmitted teenage mothers who are integrated back to school after going through the bridge center programmes and 104 readmitted teenage mothers who are integrated back to school without going through the bridge center programmes using Simple random sampling technique. The study used questionnaires for readmitted teenage mothers to collect data. Experts from the Department of Psychology and Educational Foundation in Jaramogi Oginga Odinga University of Science and Technology ascertained the face, construct and content validity of the readmitted teenage mothers' questionnaires. In this study internal consistency reliability of the instruments was obtained by computing Cronbach's alpha (a) using SPSS and a co-efficient of $r=0.783$ was reported. The data from questionnaires was analyzed using inferential statistics such as Pearson correlation, and Regression analysis. The findings indicated that the relationship between readmitted teenage mothers attitude towards Guidance and Counselling and adjustment was positive moderate and significant $(r=.550$, $n=166, p<.05)$. The study recommended that School principals should be entrusted to provide comprehensive programs to ensure holistic adjustment of the teenage mothers in schools.

Keywords: Attitude, guidance and counseling programme, adjustment, re-admitted teenage mothers, Kenyan, secondary schools

\section{Introduction}

Teenage motherhood occurring at a critical developmental stage of a teenagers' live has been identified as having adverse social and health consequences (Watts, Liamputtong \& McMichael, 
2015). Maputle (2006) asserts that teenage mothers who are pregnant for the first time experience physical emotional and psychological crisis which, depicts an identity crisis. Molborn and Morningstar (2009) observe that teenage mothers have higher levels of distress than their childless counterparts. Most teenage mothers are in transitional period between childhood and adulthood, characterized by biological, psychological and social changes. Their self-esteem is generally low and when an adolescent becomes pregnant, the psychological adjustment of pregnancy is added to the challenges in the transition of adolescence then life becomes unbearable to the teenage mother (Nyaga, 2015). According to (UNICEF, 1998; Wekesa, 2014), the girls who get pregnant are usually forced to drop out due to ridicule, stigma and hostility faced in school. It is therefore important to do a research in this area to help them cope and adjust to the challenges that they face. If they get back to school they need to be counselled in order to adjust to their new roles as mothers as well as psychologically, academically and emotionally, however many factors do affect their adjustment, for instance counselling, their socio-economic status, and their age (Chigona \& Chetty, 2008).

In Malawi, the return to school policy on readmitted teenage mothers has been on since 1995; however it has been reported that the process of applications for re-admission takes more than a more than a year. Furthermore, girls in Malawi lack counseling to combat stigma attached to teenage pregnancy, misunderstanding and pressure from teachers and fellow learners, (Chigona \& Chetty, 2008 ). Moreover, teachers are in most cases not willing to help them because they are assumed to be facing the consequences of their own behavior. The girls are also not offered professional counseling to deal with their stigma parenthood and schooling. Teachers feel that it's worth nothing and therefore do not offer them counseling when they come back to school. According to Leerlooijer, Arjan, Ruiter, Reeuwijk, Rijsdijk, Nshakira and Kok (2013) a large proportion of unmarried teenage mothers in Uganda face physical, psychological and social problems after pregnancy and childbirth, such as obstetric, complications, lack of education and stigmatization in other communities. They further did a study to explore the changes resulting from a Teenage Mothers Project (TMP) as well as factors that either enabled or inhibited these changes. The findings showed that TMP contributed to the well-being of unmarried teenage mothers and to a supportive social environment. However the present study therefore filled the gap by looking at the influence of selected factors on Adjustment of readmitted teenage mothers'.

The CSA (2008) report showed that while only $35 \%$ of girls between 16 and 20 years are in school $50 \%$ of boys the same age attend school yet enrolment of boys and girls in lower primary is almost equal. Study by Save the children \& UNFPA (2009) found that by age 19, 18\% of young women in Kenya have had a first child. In 2010, world Health Organization reported that 250 million pregnancies occurred unplanned. Teenage pregnancies remain high in Kenya at 28\% (UNFPA, 2013). In Kenya about 13,000 girls drop out yearly (CSA, 2008). The same report mentions that teenage mothers are less likely to receive social support from family, friends' and their children's fathers, making them vulnerable to mental health problems (Collins, 2010). According to a report by National Campaign to prevent Teenage and Unplanned pregnancy (2010) only $40 \%$ of teenage mums complete school, while less than $2 \%$ complete college by age 30 (Shuger, 2012). This is because they receive very little support from school and their homes; and also lack of understanding then. Kost, Henshaw and Carlin (2010) also stated that 3 out of 10 school going girls in America will get pregnant at least once before age 20. The population conducted indicated that of the 1.2 million pregnancies recorded in Uganda annually, $25 \%$ of these are teenage pregnancies. These are more than 300, 000 teenagers who get pregnant also account for the bulk of unwanted pregnancies which end up in unintended births or abortion.

These huge numbers of school going girls becoming mothers calls for professional guidance and counseling that would help them adjust to life and refocus their life to education(CSA,2008) School counselors provide counseling programs in three critical areas academic, personal or social and career. These services and programs help learners to resolve emotional social or behavioral problem and help them develop a clearer focus or sense of direction (CSA, 2008). However, the inadequacies occasioned by lack of trained guidance and counseling teachers have been detrimental in managing the menace of student pregnancy in secondary schools.

Literature on how attitude towards guidance and counselling affects adjustment among teen mothers is available. For example, Howe (2009) concluded that counselors are in a special position 
in that they can work with students to deal with factors that impede their education. Similarly, Salami (2009) study in Nigeria reiterates that students have positive attitude towards counseling; their disposition to seek counseling depends on the type of problems they have. In contrast, Mghweno and Baguma, (2013) in Uganda revealed that accessing the services showed significant correlation with students' attitude towards studies and career choice. Nkoloyakhe (2012) also add that educators have positive attitudes and are sympathetic towards pregnant teenagers, but displayed reservations about the level of skills they have with regard to helping teenagers in times of emergency like delivery in the classroom.

Similarly, Omar, Hussein and Khalid (2007), concluded that the major reasons why students are willing to seek counseling is because of the information they have about their counselor, their positive perception of the counselor and their positive attitude towards counseling. Byamugisha, Tumwine, Ndeezi, Karamagi and Trylleskar (2010) showed that the majority of the antenatal attendances (98.5\%), 382/388 had positive attitudes towards routine HIV counseling. However, Eze (2014) revealed that: Adolescents have not less than 20 permissive attitudes towards premarital sex and the views of the adolescents and adults parents on the adolescent's attitude towards premarital sex do not differ significantly. Printan (2014) revealed that most of the students were ignorant of the existence of such services and therefore students have not benefited from the programme. Similarly, Maluli and Bali (2014) showed that $75 \%$ of the participants were aware of the pregnancy policy and lamented on its staggering implementation. 95\% acknowledged the presence of quietly struggling pregnant and mothering secondary school students.

On the other hand, Eyo, and Esuong (2014) revealed that students attitude towards guidance and counseling services were significantly positive and that gender and school location significantly influenced students' attitude towards guidance and counseling services. Gatua, Sindabi and Chepchieng (2015), study indicated that guidance and counseling services in secondary schools had statistically significant impact on the level of social and emotional adjustments. Similalry, Mikaye (2012) revealed that guidance and counseling services were offered in the schools and that the principals considered it important but lacked the necessary material and literature support.

According to Ugenya Sub county Education Office (2014) there are about 242 known cases of readmitted teenage mothers distributed in 23 secondary schools in the sub-county whose ages fall between 12 to 18 years. The bridge centers under RTF project on good practice to universalize girls' access to, retention and completion of secondary school through development of demanddriven, contextually based strategies to change social norms and attitudes about girls' education in Ugenya Sub County know 318 cases of readmitted teenage mothers whose ages fall between 12 and 21 years.

\section{Research methodology}

The current study employed Ex-post facto Research Design. The target population of the study was 242 readmitted teenage mothers from selected schools in Ugenya Sub County. Fisher's formula (as reported by Creswell, 2014) was employed to select 138 readmitted teenage mothers who are integrated back to school after going through the bridge centre programmes and 104 readmitted teenage mothers who are integrated back to school without going through the bridge center programmes using to Simple random sampling technique. The study used questionnaires for readmitted teenage mothers. The questionnaires were used to obtain information on attitude towards guidance and counselling programme and also on adjustment among readmitted teen mothers. Experts from the Department of Psychology and Educational Foundation in Jaramogi Oginga Odinga University of Science and Technology ascertained the face, construct and content validity of the readmitted teenage mothers' questionnaires. In this study internal consistency reliability of the instruments was obtained by computing Cronbach's alpha ( $\alpha$ ) using SPSS and a co-efficient of $r=0.783$ was reported. The researcher obtained permission to conduct the study from the Kenyan ministry of education. The data from questionnaires was analyzed using inferential statistics such as Pearson correlation, Regression analysis and Analysis of Variance. 


\section{Findings and Discussion}

To address the research objective on the influence of attitude towards guidance and counseling on adjustment among readmitted teenage mothers', the null hypothesis was stated as follows:

$\boldsymbol{H}_{01}$ : There is no statistically significant relationship between attitude towards guidance and counseling programs and adjustment of readmitted teenage mothers in selected Kenyan secondary schools

The Pearson Moment Correlation Coefficient was used to investigate this. The $p$-value was set at .05. The null hypothesis was rejected when the p-value was less than .05 , but it was accepted when the $p$-value was greater than .05. The results were as shown on Table 1.

Table 1: Correlation between Attitudes on G \& C and Overall Adjustments among Teen Mothers.

\begin{tabular}{llc}
\hline & & Levels of Adjustment \\
\hline \multirow{3}{*}{ Attitudes Towards G\&C } & Pearson Correlation & .550 \\
& Sig. (2-tailed) & .000 \\
& $\mathrm{~N}$ & 166 \\
\hline
\end{tabular}

From Table 1, it can be observed that the relationship between readmitted teenage mothers attitude towards Guidance and Counselling and adjustment was positive moderate and significant $(r=.550$, $n=166, p<.05$ ), with increase in attitudes towards $G \& C$ resulting to improvement in adjustment. Therefore the null hypothesis that, "there is no statistically significant relationship between attitude towards guidance and counselling program and adjustment of readmitted teenage mothers in selected secondary schools in Ugenya sub-county" was rejected. This means that the attitude of the teenage mothers has relationship with adjustment of readmitted teenage mothers. That is, the more positive attitudes towards $G \& C$ the higher the adjustment among teenage mothers. This finding agrees with Gatua, Sindabi and Chepchieng (2015) who reported that guidance and counseling services in secondary schools had statistically significant impact on the level of social and emotional adjustments.

To further illustrate this relationship, a scatter plot was used show how much TM adjustment is affected by attitudes towards guidance and counselling. Creswell (2014) who recommend its use, points out that scatter diagram graphs pairs of numerical data, with one variable on each axis, to look for a relationship between them. Figure 1, shows that there was a moderate positive correlation between the two variables; the points tend to fall along the line.

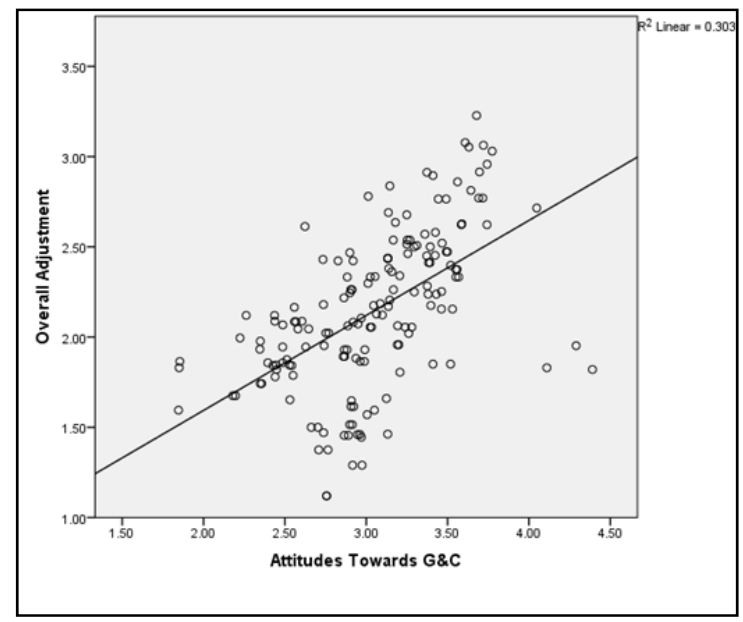

Figure 1: relationship between Attitudes towards G\&C and Adjustment of Readmitted Teenage Mothers 
The scatter plot indicates that there was a moderate positive correlation between attitudes guidance and counseling, and overall adjustment of readmitted teenage mothers to school education. This was shown by pattern of dots which inclines from lower left to upper right, demonstrating a positive correlation between the variables. The trendline further revealed that there was correlation between the variables; the coordinate points are clustered along the line, forming a visible pattern. This means that the relationship was real and not by chance.

However, to estimate the relationship between attitude of teen mother and adjustment, a coefficient of determination was computed. The results were as shown in Table 2.

Table 2: Model Summary: relationship between Attitudes towards $G$ \& $C$ and Total Adjustments among Teen Mothers.

\begin{tabular}{|c|c|c|c|c|c|c|c|c|c|}
\hline \multirow[b]{2}{*}{ Model } & \multirow[b]{2}{*}{$\mathbf{R}$} & \multirow{2}{*}{$\begin{array}{c}\mathbf{R} \\
\text { Square }\end{array}$} & \multirow[b]{2}{*}{$\begin{array}{l}\text { Adjusted R } \\
\text { Square }\end{array}$} & \multirow{2}{*}{$\begin{array}{l}\text { Std. Error of the } \\
\text { Estimate }\end{array}$} & \multicolumn{5}{|c|}{ Change Statistics } \\
\hline & & & & & $\begin{array}{l}\text { R Square } \\
\text { Change }\end{array}$ & $\begin{array}{c}F \\
\text { Change }\end{array}$ & df1 & df2 & $\begin{array}{c}\text { Sig. F } \\
\text { Change }\end{array}$ \\
\hline 1 & $.550^{\mathrm{a}}$ & 303 & 298 & .36287 & .303 & 71.164 & 1 & 164 & .000 \\
\hline
\end{tabular}

a. Predictors: (Constant), Attitudes Towards G\&C

From Table 2, it is noted that teen mothers accounted for $29.8 \%\left(R^{2}\right.$ adjusted $\left.=.298\right)$ of the variation in levels of readmitted teenage mothers' adjustment the other $70.2 \%$ was due to other factors. To determine whether readmitted teenage mothers' attitude towards guidance and counselling was a predictor of readmitted teenage mothers' levels of adjustment, ANOVA was computed (Table 3).

Table 3: ANOVA: Attitudes towards $G \& C$ and Adjustments among Teen Mothers.

\begin{tabular}{lccccc}
\hline Model & Sum of Squares & Df & Mean Square & F & Sig. \\
\hline Regression & 9.370 & 1 & 9.370 & 71.164 & $.000^{\mathrm{b}}$ \\
1 Residual & 21.595 & 164 & .132 & & \\
Total & 30.965 & 165 & & & \\
\hline
\end{tabular}

a. Dependent Variable: Overall Adjustment

b. Predictors: (Constant), Attitudes Towards G\&C

The ANOVA results revealed that attitude of teen mothers towards Guidance and Counselling was a significant predictor of levels of readmitted teenage mothers adjustment $[F(1,164)=71.164, p<$ .05], as indicated in Table 3.This means that attitudes of teenage mothers towards $G$ \& $C$ really influence adjustment of teen mothers in schools. It explains a significant amount of the variance in the value of adjustment of readmitted teenage mothers in school. However, linear regression was generated to find the actual influence of $G \& C$ on teen mothers' adjustment, as shown in Table 4.

Table 4: Coefficients of Linear Regression: Attitudes towards G \& C and Teen Mothers' Adjustment

\begin{tabular}{|c|c|c|c|c|c|c|}
\hline \multirow{2}{*}{ Model } & \multicolumn{2}{|c|}{$\begin{array}{l}\text { Unstandardized } \\
\text { Coefficients }\end{array}$} & \multirow{2}{*}{$\begin{array}{c}\begin{array}{c}\text { Standardized } \\
\text { Coefficients }\end{array} \\
\text { Beta }\end{array}$} & \multirow[t]{2}{*}{ t Sig. } & \multicolumn{2}{|c|}{$\begin{array}{l}95.0 \% \text { Confidence Interval } \\
\text { for B }\end{array}$} \\
\hline & B & Std. Error & & & $\begin{array}{l}\text { Lower } \\
\text { Bound }\end{array}$ & Upper Bound \\
\hline 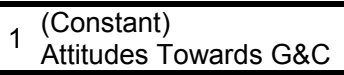 & $\begin{array}{l}.541 \\
.526 \\
\end{array}$ & $\begin{array}{l}.192 \\
.062\end{array}$ & .550 & $\begin{array}{l}2.818 \\
8.436\end{array}$ & $\begin{array}{ll}.005 & .162 \\
.000 & .403 \\
\end{array}$ & $\begin{array}{l}.920 \\
.650 \\
\end{array}$ \\
\hline
\end{tabular}

a. Dependent Variable: Overall Adjustment

Regression Equation:

$\mathrm{Y}=\mathrm{B}_{0}+\mathrm{B}_{1} \mathrm{X}_{1}+\varepsilon_{0} ; \mathrm{Y}=.541+.526 \mathrm{X}_{1}+\varepsilon_{0}$

Where $Y=$ Adjustment

$\mathrm{B}_{0}+\mathrm{B}_{1}=$ Constant

$\mathrm{X}=$ Attitudes towards G\&C

It is evident from Table 4 that if the attitude towards $G \& C$ service was increased by one standard 
deviation, then perceived scores in level of adjustment of teen mothers would increase by .550 standard deviation units. Similarly, if the attitudes of the TM increase by one unit then their level of adjustment would improve by .526 units. This is a sizable effect from one independent variable. Further, the study sought to establish the relationship between attitudes towards guidance and counseling and adjustments of the teen mothers in school, as indicated in Table 5.

Table 5: Correlation between Attitudes towards G \& C and Adjustments among Teen Mothers

\begin{tabular}{llcccc}
\hline & & Academics & Emotional & Psychological & Social \\
\hline & Pearson Correlation & .463 & .190 & .261 & .379 \\
Attitudes Towards G\&C & Sig. (2-tailed) & .000 & .014 & .001 & .000 \\
& $\mathrm{~N}$ & 166 & 166 & 166 & 166 \\
\hline
\end{tabular}

The findings of the study show that there were statistical significant positive relationship between attitudes towards guidance and counselling, and all the four aspects of adjustments among teen mothers. However, the strength of the correlations was weak positive in all the aspects of adjustments. For example, academics which had the strongest correlation $(n=166, r=.463$ and $p<$ $.05)$ was just averagely correlated to attitudes towards $G \& C$. Emotional $(n=166, r=.190$ and $p$ $<.05)$, psychological $(n=166, r=.261$ and $p<.05)$ and social $(n=166, r=.379$ and $p<.05)$ were all weak in strength in their correlation to attitudes towards $G$ \& C. Nonetheless, it was worth noting that attitudes of readmitted teenage mothers towards $G \& C$ had significant positive association with their level of adjustments to secondary school education; students with more positive attitudes are likely to exhibit faster adjustments academically, socially, emotionally and psychologically. These findings agrees with Eyo, Akon \& Esuong (2014) who reported that, students' attitude towards guidance and counseling services were significantly positive and that gender and school location significantly influenced students' attitude towards guidance and counseling services. Similarly, Omar, Hussein and Khalid (2007) found out that, major reasons why students are willing to seek counseling is because of the information they have about their counselor, their positive perception of the counselor and their positive attitude towards counseling. The cognitive adaptation theory also posits that people should enhance themselves by taking active steps in helping themselves. The enhancement is attributed to adjustment process in an effort to enhance self-esteem and restore themselves (Taylor, 1983). This helps them to return to or exceed their previous level of psychological functions.

\section{Conclusion}

Teenage mothers' attitude towards G\&C programmes enhanced their adjustment positively. This is because the study found out that improvement in attitudes towards Guidance and Counselling resulted in increase in adjustment. This was evident in the way they related to themselves and their fellow students and their willingness to share their problems and overcome their past behaviour. This shows that the attitude is very important in changing the thinking, behaviors and reshaping of academic efforts of readmitted teenage mothers. The implication of this finding is that School principals and the Guidance and counseling department should work as a team to inculcate positive attitudes among readmitted teenage mothers in schools. The study recommended that School principals should be entrusted to provide comprehensive programs to ensure holistic adjustment of the teenage mothers in schools. This would enhance their identity meaning and purpose in life as they go through the system to achieve their goals in life.

\section{References}

Byamugisha, R., Tumwire, J. K., Ndexi, G., Karamagi, C.A. \& Tylleskar, T.(2010). Attitudes to routine HIV counseling and testing, acknowledge about prevention of mother to child transmission of HIV in Eastern Uganda: A crosss sectional survey among antenatal attendees.Journal of International Aids Society 13:13-52

Center for the study of Adolescents, (CSA). (2008). Down the Drain, counting the cost of Teenage pregnancy 
and School Dropout in Kenya. Accessed on 9, June 2010. Http://www.csakenya.org/pdfs/CSA\% 20pregnancy-final\%202-Edited.pdf.

Chigona, A. \& Chetty, R. (2008). Teen Mothers and Schooling: Lacunae and Challenges. South Africa. Retrieved from http//thor.sabinet.co.za/Web/FETCH?sessionid=01-33694.

Collins, B. (2010). Resilience in Teenage Mothers: A follow up study. New Zealand. Ministry of Social Development. Welington.

Creswell, J.W. (2014). A Concase Introduction to Mixed Methods Research. Sage publication. Los Angeles. Washington D.C.

Eyo, M. \& Esuong, A. E. (2010). Attitude of secondary school students towards guidance and counselling services in cross river state. Edo Journal of Counselling Vol 3, No. 1:87-99.

Eze, I. R. (2014). Adolescents attitude towards Pre Marital Sex. Mediterranean Journal of Cosil Sciences Vo, 5 No. 10: 497-499.

Gatua, D.M., Sindabi, A.M.\& Chepchieng M.C. (2015). Impact of Guidance and Counseling services on students' behaviour modifications between selected public urban and rural secondary schools in Rift Valley Province Kenya. Research on Humanities and Social services. Vol. 5 No19:28-40.

Howe, S.A. (2009). 'School Counselling services and students' academic success". Counselors education. Master's thesis, paper 54.

Kost, K., Henshaw, S., \& Carlin, L. (2010). US teenage pregnancies, Binns and abortions: National and state trends by race and ethnicity.

Leerlooijer, J.N., Bos, A.E.R., Reller, RAC., Reeuwijk, L.E., \& Rijsdjk Nshakera kok, G. (2013). Qualitative Evaluation of teenage mothers'\& project in Uganda: A community based empowerment intervention for unmarried teenage mothers. BMC Public Health 13:816 doi:10.1186/1471-2458-13-816

Maluli, F. \& Bali, T. (2014). Exploring experiences of pregnant and mothering secondary school students in Tanzania. Research on Humanities and Social Sciences Vol. 4(1): 80-88.

Mghweno, P.E., Mghweno, L.R. \& Baguma, P. (2013). Access to guidance and counselling services and its influence on students' school life career choice. African Journal of Guidance and Counseling 1 (1):007015.

Mikaye, D.O. (2012). Influence of Guidance and Counseling on students discipline in public secondary schools in Kabondo Division Kenya. MA Thesis University of Nairobi.

Mollborn, S. \& Morningstar, E. (2009). Investigating the relationship between teenage child bearing and psychological distress using longitudinal evidence. The Journal of Health and Social Behaviour, 50: 310326.

Nkoloyakhe, D. (2006). Education attitudes towards teenage pregnancy. Published Master's Thesis, University of Zululand.

Nyaga, F.G. (2015). Relationship between social support and self-esteem among Teenage mothers attending Pumwani Maternity hospital in Nairobi County, Kenya. Published M.A Thesis, Kenyatta University.

Printan, P.N. (2014). An Assessment of the Guidance and Counseling programme in Secondary schools at Mzilikazi District in Bulawayo Metropolitan province. Journal of Humanities and Social Sciences. 19 (1): 81-90.

Shuger, L. (2012). Teen pregnancy and High school dropout: what communities are doing to address these issues. Washington DC. The National campaign to prevent teen and unplanned pregnancy and America's promise alliance (online). www.the nationcampaignorg/resources/pdf/teen-preg-hs-dropout.pdf.

Watts,C.,N., Liamputtong, P. \& Mcmichael. C., (2015). Early Motherhood: A Qualitative Study. Exploring the experiences of African Australian teenage mothers in greater Melbourne, Australia. BMC Public Health. 15 (2):873-891 DOI:10.1186/5/12889-015-22-15-2.

Wekesa, V. (2014). Re-admission policy and KCSE performance in Bungoma North Sub-county, Kenya. International Journal of Innovative Research and Development. Vol. 3(7):436-441. 